\title{
El ganado criollo colombiano Sanmartinero, su conservación y aporte sostenible a la producción bovina en la Orinoquia colombiana
}

\author{
Germán Martínez Correal ${ }^{1} \bowtie$ Hernando Flórez Díaz $^{2} \llbracket$ @ Germán. C. Martínez-Villate 3 \\ Asociación de Criadores de Bovinos de Razas Criollas y Colombianas de los Llanos Orientales, ASOCRIOLLANOS. Villavicencio, Meta, Colombia.

\section{Colombian creole cattle Sanmartinero, its conservation and sustainable contribution to bovine production in the Colombian Orinoquia}

\begin{abstract}
This article highlights historical aspects of the origin of Colombian Creole cattle, with an emphasis on Sanmartinero (SM) cattle, which developed in the foothills and altillanura of the Colombian Orinoquia region, thanks to the work of natural selection and the zootechnical effort of the Jesuits, in the seventeenth century, with cattle introduced by the Spanish in the fifteenth century. Aspects related to its recent history are presented from the beginning of its conservation in the Granja Iracá (San Martín, Meta) and its subsequent transfer to the Research Centers (CI) of the Colombian Agricultural Institute ICA, La Libertad, in the piedemonte llanero in Villavicencio (Meta) and Carimagua in the Colombian altillanura (Puerto Gaitán, Meta), centers that since 1994 have been in possession of the Colombian Corporation of Agricultural Research, AGROSAVIA. The main research results carried out in the CI La Libertad related to all biological and economic aspects of the conservation, characterization and use of the breed are summarized. Similarly, results of the use of the breed in cow-calf systems (meat) and dairy (dual purpose) are presented in farms of pure and commercial breeders. Their qualities and productive skills are described as purebred and in crossbreeds - heterosis - with other breeds, especially with commercial Cebu (C) type Brahman. Of all research experiences and positive results, especially of the adaptive characteristics - fertility, longevity, climate resistance, parasites and endemic diseases - and to their great combinatorial ability to produce heterosis it can be concluded that the SM is one of the best competitive and sustainable alternatives to improve the production, profitability and quality of the final product, mainly meat, of the cow-calf and dairy systems of the Colombian Orinoquia.
\end{abstract}

Keywords: Local breeds, beef cattle, heterosis, crossbreeding.

Resumen. Este artículo resalta aspectos históricos del origen de los ganados criollos colombianos, con énfasis en el bovino de raza Sanmartinero (SM), el cual se desarrolló en el piedemonte y altillanura de la región de la Orinoquia colombiana, gracias al trabajo de la selección natural y al esfuerzo zootécnico de los jesuitas, en el siglo XVII, con los bovinos introducidos por los españoles en el siglo XV. Se presentan aspectos relacionados con su historia reciente a partir del inicio de su conservación en la Granja Iracá (San Martín, Meta) y su posterior traslado a los Centros de Investigación (CI) del Instituto Colombiano Agropecuario ICA, La Libertad, piedemonte llanero en Villavicencio (Meta) y Carimagua en la altillanura colombiana (Puerto Gaitán, Meta), centros que desde el año 1994 han estado en poder de la Corporación Colombiana de Investigación Agropecuaria, AGROSAVIA. Se resumen los principales resultados de investigación, llevados a cabo en el CI La Libertad referentes a todos los aspectos biológicos y económicos de la conservación, caracterización y utilización de la raza. Igualmente, se presentan resultados de la utilización de la raza en sistemas de cría (carne) y leche (doble propósito) en fincas de criadores puros y comerciales. Se describen sus cualidades y aptitudes productivas, como raza pura y en cruces - heterosis - con otras razas, especialmente con Cebú comercial (C) tipo Brahman. De todas las experiencias de investigación y resultados positivos, especialmente de los caracteres adaptativos - fertilidad, longevidad, resistencia al clima, parásitos y enfermedades endémicas - y a su gran habilidad combinatoria y para producir heterosis se puede concluir que el SM es una de las mejores alternativas competitivas y sustentables para mejorar la producción, rentabilidad y calidad del producto final, principalmente carne, de los sistemas de cría y leche de la Orinoquia Colombiana.

Palabras clave: Razas locales, ganado de carne, heterosis, cruzamientos.

Recibido: 2020-07-30. Aceptado: 2020-10-22.

${ }^{1}$ Autor para la correspondencia: amicriollanos@gmail.com

${ }^{2}$ Corporación Colombiana de Investigación Agropecuaria, AGROSAVIA, Villavicencio, Meta, Colombia.

3Ejercicio particular, Bogotá D. C., Colombia. 


\section{Gado crioulo colombiano Sanmartinero, sua conservação e contribuição sustentável para a produção bovina na Orinoquia colombiana}

Resumo. Este artigo destaca aspectos históricos da origem do gado crioulo colombiano, com ênfase no bovino da raça Sanmartinero (SM), desenvolvido no sopé e no sótão da região colombiana de Orinoquia, graças ao trabalho de seleção natural e ao esforço zootécnico dos jesuítas, no século XVII, com o gado introduzido pelos espanhóis no século XV. Aspectos relacionados à sua história recente são apresentados desde o início de sua conservação na Fazenda Iracá (San Martín, Meta) e sua subsequente transferência para os Centros de Pesquisa (CI) do Instituto Agrícola Colombiano ICA, La Libertad, no sopé das planícies em Villavicencio (Meta) e Carimagua no altillanura colombiano (Puerto Gaitán, Meta), centros que desde 1994 são mantidos pela Corporação Colombiana de Pesquisa Agrícola, AGROSAVIA. Os principais resultados da pesquisa são resumidos, realizados na CI La Libertad referentes a todos os aspectos biológicos e econômicos da conservação, caracterização e uso da raça. Da mesma forma, são apresentados os resultados do uso da raça em sistemas de criação (carne) e leite (duplo propósito) em fazendas de criadores puros e comerciais. Suas qualidades e aptidões produtivas são descritas como uma raça pura e em cruzamentos - heterose - com outras raças, especialmente no comercial Brahman do tipo zebu (Z). De todas as experiências de pesquisa e resultados positivos, especialmente as características adaptativas - fertilidade, longevidade, resistência ao clima, parasitas e doenças endêmicas - e sua grande capacidade combinatória e de produzir heterose, pode-se concluir que SM é uma das melhores alternativas competitiva e sustentável melhorar a produção, a lucratividade e a qualidade do produto final, principalmente carne, proveniente dos sistemas agropecuário e de leite da Orinoquia colombiana.

Palabra chave: raças locais, gado de corte, heterose, cruzamentos

\section{Introducción}

El bovino Sanmartinero (SM) forma parte del inventario de recursos genéticos criollos colombianos, originados de los animales Bos taurus introducidos en el siglo XV por los conquistadores españoles. Hasta comienzos del siglo XX fueron la base genética de los sistemas de producción bovina, especialmente los ubicados en el trópico bajo colombiano, el 80 \% del territorio del país, y en donde se desarrollan los sistemas de producción de cría (carne) y doble propósito (carne - leche). Este recurso genético se formó en el piedemonte llanero, Orinoquia colombiana, gracias al trabajo de la selección natural, y al esfuerzo zootécnico de los jesuitas, en el siglo XVII. Desde su introducción, los animales fueron sometidos a un proceso de selección natural que les permitió adquirir características adaptativas de importancia económica como fertilidad, rusticidad, longevidad, tolerancia a enfermedades y parásitos, y habilidad para soportar condiciones extremas de temperatura y humedad y para utilizar forrajes fibrosos. De esta forma, el SM se constituye en patrimonio biológico y económico para la provisión sostenible de alimentos (carne, leche), pieles y trabajo en la Orinoquia colombiana $\mathrm{y}$, por consiguiente, para apoyar la seguridad y soberanía alimentaria del país. No obstante, las favorables características económicas, su población se encuentra en riesgo de extinción, debido principalmente a su sustitución mediante cruzamientos absorbentes indiscriminados con otras razas, especialmente el Cebú (Brahman) introducida a comienzos del Siglo XX. El mejor comportamiento productivo de los híbridos, obtenido con toros de razas introducidas, fue atribuido, por desconocimiento de las leyes de la herencia, al aporte genético de éstas y no a la combinación favorable de genes no aditivos y a la habilidad combinatoria que se generó al cruzar estas razas. El objetivo de esta revisión sobre el bovino criollo colombiano Sanmartinero (SM) es hacer un análisis sucinto sobre su origen y destacar las acciones de conservación, caracterización y utilización; de igual manera, resaltar las bondades adaptativas y por ende su contribución sostenible y competitiva en sistemas de cría (carne), especialmente aquellos de índole extensivo y de uso limitado de insumos externos.

\section{Área de influencia}

El ganado SM está adaptado a las subregiones del piedemonte y altillanura de la región Orinoquense, representativas según Holdrige y Hunter, 1961 de las zonas de bosques húmedo tropical (BHT) y muy húmedo tropical (BMHT), las cuales se caracterizan por tener topografías planas y onduladas, suelos ácidos, con deficiencias minerales, especialmente de $\mathrm{P}$, $\mathrm{Cu}, \mathrm{Zn}, \mathrm{y}$ altos contenidos de $\mathrm{Al}$.
La altitud donde se desarrolla este ganado varía desde 450 hasta $200 \mathrm{~m}$, en el piedemonte y altillanura, respectivamente; temperatura media de $26{ }^{\circ} \mathrm{C}$ con variaciones bruscas durante las 24 horas del día; humedad relativa de $87 \%$ en la época lluviosa (abril a noviembre) y de $55 \%$ en la época seca (noviembre a marzo). La precipitación varía entre 2700 (altillanura) y 3500 (piedemonte) mm/año. (Santos, 1983)

ISSN-L 1022-1301. Archivos Latinoamericanos de Producción Animal. 2020. 28 (3-4): 69-86 
Las principales gramíneas nativas de las dos subregiones son el Pasto Negro (Paspalum plicatulum), Gramalote (Paspalum fasciculatum), Guaratara (Axonopus purpussi), Lambedora (Leersia hexandra), Carretera (Parateria prostrata), y variedades de pajas del llano como la Paja Peluda (Trachypogon vestitus). Entre las principales gramíneas introducidas se encuentran los Brachiaria sp. decumbens, humidicola, dictyoneura, bryzantha, y el Pasto Puntero (Hyparrhenia rufa). Entre las leguminosas existentes merecen mencionarse el Kudzú (Pueraria phaseoloides), Maní Forrajero (Arachis pintoi), Pega Pega (Desmodium sp.), y otras especies nativas sin clasificar (Huertas, 1998).

\section{Situación actual}

Hasta comienzos del siglo XX, el SM era la raza más utilizada para la producción de carne y leche en la altillanura y piedemonte del departamento del Meta; sin embargo, en la reciente encuesta para cuantificar las poblaciones actuales de los recursos genéticos de especies domésticas de Colombia (FAO - DAD-IS, 2018), se estimó que la población actual de animales puros está entre 2162 y 2558 cabezas, la mayoría de ellas en el piedemonte y altillanura del departamento del Meta, distribuidas en hatos de multiplicación y fomento de la Secretaría de Agricultura del Meta, (Granja Iracá - San Martín) y de criadores particulares y 796 cabezas en los bancos de germoplasma y núcleos de selección de la Corporación colombiana de investigación agropecuaria, AGROSAVIA, en los centros de investigación La Libertad (Villavicencio) y Carimagua (Puerto Gaitán) para un gran total de 3354 cabezas (Delgado et al., 2020).

\section{Breve Reseña Histórica}

En el segundo viaje de Colón (1493) se embarcaron, junto con equinos, ovinos y porcinos, los primeros bovinos con destino a la isla La Española (hoy Santo Domingo) (Rouse, 1977). Las poblaciones ancestrales ibéricas, sin denominación o diferenciación racial, que dieron origen, tanto a las razas autóctonas españolas actuales como a nuestros vacunos criollos, provenían de la mezcla de los bovinos Bos taurus de Europa Central, y de los africanos (Sanga) introducidos a la península Ibérica durante la época de invasión de los moros (De Alba, 2009; Villalobos-Cortés et al., 2009).

El 29 de julio de 1525, Don Rodrigo de Bastidas desembarcó en la bahía de Santa Marta, Nueva Granada, con 200 bovinos entre toros, vacas y crías, los que se consideran hoy como los ancestros de la mayoría de las razas criollas colombianas (Pinzón, 1991). Sobre el origen de los bovinos que constituyeron los ancestros más cercanos de la raza Sanmartinera existen muchos reportes que lo señalan como provenientes de Venezuela (Pinzón, 1991; Abrew, 1999); sin embargo, Huertas y Huertas (2015) señalan que los bovinos que dieron origen al SM fueron introducidos por Juan de Avellaneda a San Juan de los Llanos (hoy San Juan de Arama) y que posteriores asentamientos ganaderos se dieron con el Adelantado del Nuevo Reino de Granada Alonso Luis de Lugo en 1542-43 y Gonzalo Jiménez de Quesada (1569).

Durante los siglos XVII y XVIII, la Comunidad Jesuita de San Ignacio de Loyola asentada en los llanos colombianos y parte de la cordillera Oriental, contribuyó a la conservación y desarrollo del hato criollo SM. La ruta Europa - América, por la vía de los ríos Orinoco y Meta, posibilitó el ingreso de nuevos bovinos españoles. En el año 1896, la Compañía Colombia de Herrera y Lorenzana, con asentamientos en San Martín, importó de Inglaterra toros Shorthorn para ser cruzados con vacas SM; ese mismo año llegaron por la vía Orinoco y Meta, los primeros toros Cebú con destino al Meta. Por la misma época, don Emiliano Restrepo Echavarría, dueño de la hacienda Vanguardia, Villavicencio, importó de Inglaterra reproductores Hereford con los que, se dice, realizó los cruzamientos para formar la "sub raza" SM de doble propósito, la cual, para el año 1920, registraba producciones de 30 botellas de leche por vaca/día (Pinzón, 1991; Abrew, 1999).

En un estudio de la huella genética de los ganados ibéricos en América (Martínez et al., 2012), se evaluó la diferenciación genética entre los criollos y los bovinos ibéricos, europeos y cebuínos. Las distancias genéticas mostraron un clúster del SM con los criollos mejicanos y el Texas Longhorn que se encuentra muy relacionado con el ganado ibérico, pero con poca influencia de las razas continentales y del Cebú.

El origen del ganado ibérico y la validez de las teorías se remontan a tiempos tan lejanos que esta discusión se haría interminable. En resumen, todos los autores están de acuerdo en afirmar que las razas criollas de América descienden de los ganados provenientes de la península Ibérica y que fueron traídos por los conquistadores en los albores del Siglo XV. 


\section{Programas de Conservación y Caracterización}

Las pequeñas poblaciones de bovinos criollos existentes en el país sobreviven gracias a los esfuerzos del Estado colombiano. En el periodo alrededor de 1930, el Ministerio de Agricultura de Colombia, consciente del valor económico que los animales criollos tenían para la producción y en consideración a la drástica reducción de la población que se venía presentando, estableció los primeros grupos de conservación, en 1936, en la Granja de Montería (Costa Atlántica) con ganado Romosinuano (Romo); en 1940, en Valledupar (Costa Atlántica) y en El Nus (zona montañosa de la Cordillera Central) con ganados Costeño con Cuernos (CCC) y Blanco Orejinegro (BON), respectivamente. Otras entidades oficiales sectoriales iniciaron programas de conservación de los bovinos Hartón del Valle (HV), Chino Santandereano (Chino) y Casanareño (Cas) (Pinzón, 1991).

\section{Características Zootécnicas}

\section{Características morfológicas y fisiológicas}

El ganado SM por su conformación se clasifica como mesolíneo y por su tamaño como eumétrico. La alzada, medida en la vertical de la cruz, es de 130 y $135 \mathrm{~cm}$, para hembras y machos, respectivamente. El cuerpo alargado, con mayor desarrollo del tren anterior en los machos, tiene cuello voluminoso, tórax profundo y dorso largo. El perímetro torácico en las vacas es de $178 \mathrm{~cm}$, y de $185 \mathrm{~cm}$ en los toros. La línea dorsal es ligeramente débil, el anca caída y desprendimiento de cola alto, con pecho ancho, costillas arqueadas y grupa alargada (González, 1999).

Los animales SM tienen cabeza grande y fuerte con perfil rectilíneo; orejas pequeñas, redondeadas y con abundante cantidad de pelos. Cuernos fuertes y bien implantados, de color claro en la raíz con tonos más oscuros en las puntas; en los machos son gruesos y dirigidos hacia delante en forma de corona, mientras que en las hembras son en forma de lira (retorcidos hacia delante, hacia atrás y arriba). Sus extremidades son proporcionales al cuerpo y con aplomos sólidos. Su cola es gruesa y larga, que termina en una borla abundante de pelos largos, cuyo color está de acuerdo

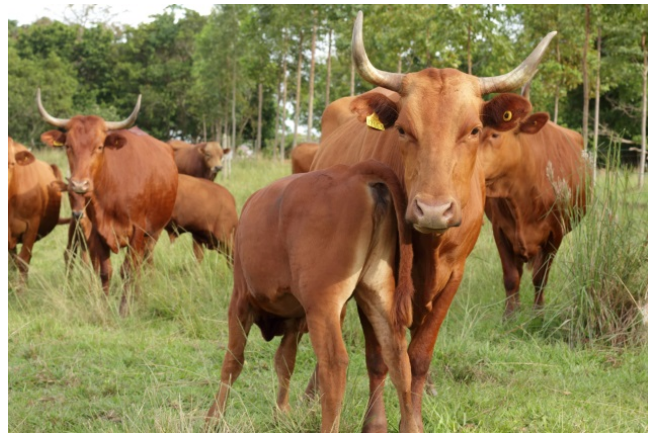

Figura 1. Vaca y cría Sanmartinero.
En el año de 1950, en la granja de Iracá situada en el municipio de San Martín, Meta (piedemonte llanero de la Orinoquia), se conformó el primer grupo de ganado SM. El hato inicial fue dividido y parte de éste pasó luego al CI La Libertad (1959, Villavicencio), entonces regido por el Departamento de Investigaciones Agropecuarias (DIA) del Ministerio de Agricultura, y en el año 1962 por el recién creado Instituto Colombiano Agropecuario (ICA). En el año de 1969 se llevó una parte del hato de La Libertad para el CI Carimagua del ICA, localizado en la altillanura de la Orinoquia colombiana (Puerto Gaitán, Meta). Paralelamente a la estrategia de conservación, el DIA primero, luego el ICA y actualmente AGROSAVIA han llevado a cabo las acciones de conservación, fomento y caracterización genética de la raza (Pinzón, 1991).

con el color del animal. La piel tiene un grosor aproximado de $12 \mathrm{~mm}$, es pigmentada de color negro o marrón definidos y en algunos casos se encuentra moteada. El color de las mucosas corresponde al color del pigmento predominante. El pelo es de longitud media, $5 \mathrm{~mm}$, no es grasoso y se han contado entre 6 y 7 mil pelos por cm2. El color del pelo, como en la mayoría de las razas criollas, es amarillo con tres tonalidades: Bayo, Colorado y Hosco (González, 1999); sin embargo, Martínez y Chaves (2001), encontraron, en poblaciones aisladas de la altillanura colombiana, animales negros, pardos, overos, isabelas y barcinos.

El sistema mamario es poco profundo, con ubre bien implantada; medida en $\mathrm{cm}$ tiene 30 de altura, 25 de longitud, 33 de ancho y 17 de profundidad. Las venas mamarias son prominentes con un diámetro de $2 \mathrm{~cm}$. La conformación de la ubre no es estética, ya que los pezones delanteros, de $6.5 \mathrm{~cm}$, son más largos que los posteriores, de $4.7 \mathrm{~cm}$. En forma similar, el perímetro de $9.5 \mathrm{~cm}$ de los pezones anteriores superan los $8.2 \mathrm{~cm}$ de los posteriores. Los testículos son firmes y bien proporcionados con circunferencia escrotal media de $38 \mathrm{~cm}$ en animales adultos (González, 1999; Martínez y González, 2000).

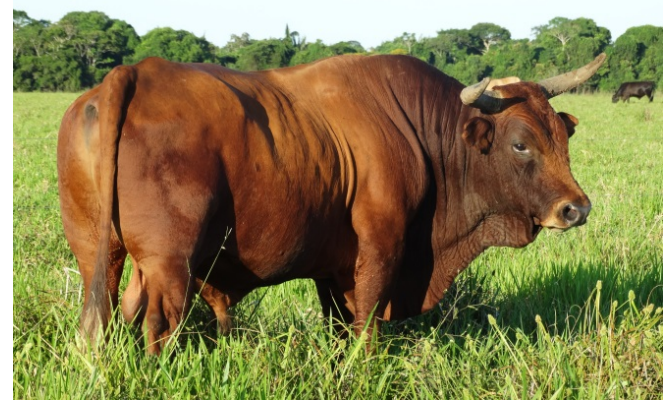

Figura 2. Toro Sanmartinero.

ISSN-L 1022-1301. Archivos Latinoamericanos de Producción Animal. 2020. 28 (3-4): 69-86 
Ventajas adicionales del toro SM, sobre los cebuinos y otros Bos taurus de origen europeo (continentales o británicos), como producto de su adaptación, son una mayor capacidad de cubrimiento de hembras y longevidad reproductiva (Martínez y González, 2000). En muchas ocasiones, se usa estimar el doble de hembras (50) que las que se consideran como normales (25) para un reproductor de otra raza (Martínez y Chaves, 2001) y no es raro encontrar toros con 80 o más hembras sin que, como dice el llanero, se "culatien", es decir sin que sufran de agotamiento sexual; su longevidad reproductiva se estima en más de diez años. La única forma de mantener quietos a los reproductores en el hato es rodeándolos de un numeroso grupo de vacas fértiles. El toro SM es, además, un campeón y perspicaz economista de su gran capacidad sexual: no trabaja en horas calurosas, prefiere la luz de la luna; no se desgasta repitiendo el salto o monta a una misma hembra, prefiere buscar otras hembras en celo y de ahí que cumple con creces con la finalidad de producir mayor cantidad de crías que toros de otras razas.

Una de las particularidades de importancia económica en las hembras SM es su facilidad de parto puesto que la expulsión del feto, con la vaca en posición de pie, en el $86 \%$ de los casos, ocurre en aproximadamente 5 minutos (Velásquez, 1999), lo cual está relacionado con el pequeño tamaño de sus crías al nacer, factor que favorece la rápida recuperación posparto de las hembras y permite, en consecuencia, una acelerada reconcepción (Martínez, 1999). La placentofagia es evidente y esta aptitud provee, secundariamente, protección a las crías de las aves de rapiña. El tiempo que la cría requiere para ponerse de pie y amamantar es inferior a la hora. Todos estos atributos de comportamiento no son otra cosa que manifestaciones de adaptación. La docilidad y habilidad para cubrir largas distancias son sus principales características de comportamiento y por tanto cualidades que facilitan su manejo y adaptación a grandes extensiones. Su fortaleza y presencia de cuernos de fuerte consistencia e implantación lo habilitan, además, como un animal de tiro y carga, y como un hábil repeledor del ataque de depredadores felinos (pumas, jaguares).

Los toros criollos y en particular el SM producen terneros muy livianos al nacimiento, hecho que concuerda con los hallazgos de investigaciones con BON y Romo (Hernández, 1981; Martínez et al., 1994). Esta característica, sumada a la mayor supervivencia de sus crías, es una cualidad de suma importancia pues las vacas SM presentan menores dificultades al parto, y por tanto una más rápida involución uterina, pronta reconcepción y, en consecuencia, menor IEP.
Los animales SM y sus híbridos con C poseen una resistencia intermedia al estrés calórico entre el $\mathrm{C}$ y razas Bos taurus como el Holstein Friesian. El SM utiliza como principal mecanismo para disipar calor el aumento de la frecuencia respiratoria, pero, a diferencia del Holstein, no aumenta su profundidad, lo que garantiza su status ácido-básico, hecho demostrado por la no alteración del pH sanguíneo (Velásquez et al., 1998a). Los terneros SM tienen, al nacer, mayor proporción de niveles protectores de inmunoglobulinas séricas que los $\mathrm{C}$, factor que les garantiza una mayor probabilidad de supervivencia (Gómez et al., 2000). En forma similar, se encontró que el SM y sus híbridos con $\mathrm{C}$ poseen una resistencia intermedia a las garrapatas entre el $\mathrm{C}$ y cruces de éste con razas de origen europeo (Villar y Martínez, 1996).

Diversas investigaciones han demostrado que, bajo condiciones de estrés por calor, novillas y vacas SM (Velásquez et al., 1996a, Velásquez et al., 1998b) mantienen la temperatura rectal cercana a $39{ }^{\circ} \mathrm{C}$ (temperatura normal), mostrando un nivel de tolerancia similar al del ganado Bos indicus representado por el $\mathrm{C}$ tipo Brahman y mayor que el de razas Bos taurus como el Holstein y el Angus. La tolerancia al calor también se ha mostrado en animales jóvenes, debido a que la temperatura rectal de terneros SM y C sometidos a estrés por calor (bajo radiación solar directa) es similar entre el primer mes de vida y el destete, indicando un buen grado de termorregulación de la raza criolla (Velásquez et al., 1998a).

Adicionalmente, durante condiciones de estrés por calor, los bovinos SM pierden más calor por la respiración que los bovinos C. Las investigaciones han mostrado que novillas SM (48 resp/min) sometidas a estrés por calor presentan mayor frecuencia respiratoria en comparación con novillas C (36 $\mathrm{resp} / \mathrm{min}$ ), pero menor frecuencia respiratoria que novillas Holstein (111 resp/min) o Angus (69 resp/min) (Velásquez et al., 1998b).

Entre el nacimiento y el destete, los terneros SM tienen menor porcentaje de hematocrito y hemoglobina que los terneros C. En condiciones de estrés por calor, la presión parcial de oxígeno y el pH sanguíneo son mayores en terneros neonatos SM que en terneros C (Velásquez et al., 1996b; Velásquez, 1999). Sin embargo, en novillas y vacas SM, en comparación con el C, no se observaron cambios en el equilibrio ácido-base ni en el pH sanguíneo (González et al., 1996; Velásquez et al., 1998b), lo que indica una buena capacidad de termorregulación en los animales adultos de las razas criollas, similar a la que se observa en razas tolerantes al calor como el C. En terneros SM 
se presentó disminución del hematocrito, hemoglobina, y proteínas totales entre el tercer y cuarto mes de vida, lo cual coincidió con el cambio de prerumiante a rumiante y con el inicio de la época de lluvias en la región del Piedemonte del Meta (Velásquez et al., 1996c).

Cuando se compararon las temperaturas del color de la capa de novillas SM, C y Holstein mantenidas bajo sol en las condiciones del Piedemonte Llanero, se observó que la temperatura fue menor en el C (36.4 $\left.{ }^{\circ} \mathrm{C}\right)$, intermedia en el SM $\left(41.7^{\circ} \mathrm{C}\right)$ y mayor en Holstein $\left(44.7{ }^{\circ} \mathrm{C}\right)$ (Velásquez et al., 1998b), lo que además sugirió en este estudio, que animales con pelajes oscuros tendieron a absorber mayor radiación solar que animales con pelajes claros.

\section{Sobrevivencia neonatal}

Otro factor de adaptación al trópico es la viabilidad y la capacidad de sobrevivencia de los terneros recién nacidos. Los terneros criollos SM presentaron mayor viabilidad que los terneros $\mathrm{C}$ y del sistema doble propósito. Por ejemplo, después del nacimiento, terneros SM se pararon e ingirieron calostro por primera vez más rápido (40.5 vs $47.9 \mathrm{~min}$ ) que los terneros C (Gómez et al., 2000). Algunos estudios en los Llanos Orientales mostraron que los terneros SM presentaron mayor absorción de anticuerpos del calostro en comparación con terneros $\mathrm{C}$ o del sistema doble propósito (Flórez et al., 1998; Gómez et al., 2000). Además, entre el nacimiento y el destete, los terneros con mayor absorción intestinal de anticuerpos calostrales presentaron mayor ganancia diaria de peso corporal (653.7 g/animal/d) en comparación con terneros con baja absorción (352.5 g/animal/d) (Flórez et al., 1998).

\section{Reproducción en la vaca y el toro}

En general, las novillas criollas SM obtienen la pubertad a menor edad y peso que las novillas C. Adicionalmente, las vacas criollas SM presentan mejor comportamiento reproductivo que vacas C. Estudios realizados en el CI La Libertad mostraron que las vacas SM entraron en calor antes de los $70 \mathrm{~d}$ posparto y quedaron preñadas antes de los $98 \mathrm{~d}$. De forma similar, la proporción de vacas en anestro posparto fue inferior al $5 \%$ en vacas SM (Velásquez et al., 2000).

A nivel de campo, los toros criollos SM presentan una mayor fertilidad que los toros $\mathrm{C}$ y otras razas foráneas. Esto es el resultado de un semen de mayor volumen, motilidad y concentración (Jiménez et al., 1996). Estos resultados también han sido confirmados a nivel de laboratorio. En estudios de evaluación in vitro, la capacidad de penetración de ovocitos bovinos por parte del espermatozoide, la cual es un indicador confiable de la capacidad fertilizante del semen in vivo, se observó que los porcentajes de penetración fueron mayores en toros SM (49.7 \%) que en toros C (45.2 \%) y Holstein (42 \%), indicando mayor capacidad fertilizante en el semen bovino criollo (Obando et al., 1999).

\section{Características Productivas}

El hato de conservación de la raza, en los CI La Libertad y Carimagua, fue manejado en lotes de apareamiento, conformando grupos de 25 a 30 vacas (lactantes, secas y novillas) por toro; se utilizó una temporada de monta en la época de lluvias (mayo a junio) buscando la mayor disponibilidad forrajera, para un buen desempeño reproductivo y para que los nacimientos ocurrieran en la temporada seca (febrero a abril), procurando mejor desarrollo y bienestar de las crías, por los menores inconvenientes ambientales, especialmente los referentes a presencia de plagas y parásitos (Martínez y González, 2000).

La consanguinidad se controló, hasta el año 1991, evitando apareamiento de animales estrechamente relacionados (Padre - hija; hijo - madre; hermanos medios y completos y primos hermanos, tíos y sobrinos). En 1991, cada uno de los hatos se dividió en familias, ocho en La Libertad y seis en Carimagua, de acuerdo con el parentesco de los animales y se inició el sistema de apareamiento circular conforme Kimura y Crow (1963), el cual consiste en aparear los machos de la primera familia con las hembras de la segunda; los de la segunda con las hembras de la tercera y así sucesivamente hasta cerrar el círculo de las ocho familias. Cada tres años del anterior ciclo, los apareamientos se hacen "saltando" una familia (Martínez, 2013).

\section{Reproducción y supervivencia}

Los valores medios de rasgos reproductivos, edad al primer parto (EPP) e intervalo entre partos (IEP), de pesos al nacer y crecimiento pre y posdestete, los valores medios de peso adulto (mayores de 4 años) y los índices de herencia $\left(\mathrm{h}^{2}\right)$ del SM, entre los años 1971 y 1996 en el CI La Libertad, se presentan en la Cuadro 1. 
Cuadro 1. Valores medios de rasgos de reproducción, crecimiento e índices de herencia ( $\mathrm{h}^{2}$ ) en el hato Sanmartinero (SM) de conservación del CI La Libertad, 1971-1996.

\begin{tabular}{lccc}
\hline Característica & Machos & Hembras & $\mathrm{h}^{2}$ \\
\hline Edad al primer parto, d & & 989.15 & $0.34^{*}$ \\
Intervalo entre partos, d & & 439.42 & $0.09^{*}$ \\
Peso al nacer, kg & 27.7 & 26.3 & $0.26^{*}$ \\
Peso 8 meses, kg & 172.3 & 161.0 & $0.14^{*}$ \\
Peso 16 meses, kg & 233.0 & 215.0 & - \\
Peso adulto > 4 años, kg & 650.0 & 450.0 & - \\
Ganancia diaria predestete, g/d & 600.0 & 600.0 & $0.54^{*}$ \\
Ganancia diaria posdestete, g/d & 254.1 & 225.0 & 0.30 \\
Adaptado de: Elzo et al., 1999; Martínez y Chaves, 2001; Martínez et al., 2009a; Martínez et al., 2009b
\end{tabular}

Los pesos a las diferentes edades son muy similares a los de otras razas criollas colombianas como el BON y Romo y corresponden a animales de tamaño mediano, moldeados por las limitantes ambientales del trópico, especialmente las nutricionales. Hernández (1981), encontró, para pesos al nacer, 27 y $29.6 \mathrm{~kg}$, destete, 177.8 y $188 \mathrm{~kg}$, para BON y Romo, respectivamente. La $\mathrm{h}^{2}$ de IEP y peso al destete son de baja magnitud (< 0.15); mientras que las de EPP, peso al nacer, y ganancias predestete y posdestete son valores medios (0.26 a 0.54), indicando que la seleccion sería efectiva en dichos caracteres.

Martínez et al., (1998) analizaron, en vacas SM, el efecto del tamaño, tomado como la altura al sacro, sobre la reproducción y encontraron que la altura al sacro varió entre 123 y $145 \mathrm{~cm}$. Las vacas se clasificaron en tres categorías: pequeñas entre $123 \mathrm{y}$ $130 \mathrm{~cm}$, medianas entre 130.1 y $138 \mathrm{~cm}$, y altas entre 138.1 y $145 \mathrm{~cm}$. Las vacas pequeñas y medianas presentaron las menores EPP (1118 y 1137 d), aventajando a las altas (1220) en 102 y 83 d; similarmente, las vacas pequeñas presentaron el menor IEP (409 d), aventajando en 23 y $70 \mathrm{~d}$ a las medianas y altas, repectivamente. No se observaron diferencias en los pesos al destete (PD, 8 meses), pero si en la relación $\mathrm{PD} /$ Peso de la vaca al destete de la cría (PD/PV); las vacas pequeñas destetaron más $\mathrm{kg}$ de ternero con relación a su propio peso, $0.369 \mathrm{~kg} / \mathrm{kgV}$ que las medianas $0.351 \mathrm{~kg} / \mathrm{kgV}$ y altas $0.338 \mathrm{~kg} / \mathrm{kgV}$, corroborando otros estudios que indican mayor eficiencia reproductiva de vacas de menor tamaño (Laborde et al., 1998).

\section{Cruzamientos}

Paralelo al programa de conservación y caracterización de la raza, se llevó a cabo un plan de cruzamiento dialélico, utilizando toros SM sobre vacas C comerciales con predominio de herencia de Brahman, la raza cebuína que más abunda en Colombia y toros Brahman puros sobre hembras SM, con el fin de medir valores de heterosis individual (efectos no aditivos); así mismo, con el propósito de conocer valores de heterosis materna, se hicieron cruzamientos terminales con toros de terceras razas, Charolais (Ch) y Santa Gertrudis (SG), apareados con hembras puras $\mathrm{SM}, \mathrm{C}$, y sus $\mathrm{F} 1$ recíprocas, $1 / 2 \mathrm{SM} \times 1 / 2 \mathrm{C}$ y $1 / 2 \mathrm{C} \times 1 / 2 \mathrm{SM}$. En todos los casos anteriores, el apareamiento fue manejado en monta estacional como en los lotes del núcleo de conservación de la raza, en lotes mixtos, es decir hembras (lactantes, secas y novillas) de las distintas composiciones raciales con el correspondiente reproductor, SM, C, Ch, SG. En el Cuadro 2 se presentan los resultados de natalidad, sobrevivencia hasta el destete y tasa de destete de varios de los grupos de apareamiento llevados a cabo en el CI La Libertad durante los años 1971 a 1986.

Cuadro 2. Tasas de natalidad, mortalidad y destete en diferentes grupos de apareamiento de Sanmartinero (SM), Cebú (C) y sus cruces con Charolais (Ch) y Santa Gertrudis (SG). Centro de Investigación La Libertad. 1971-1986.

\begin{tabular}{cccccc}
\hline Raza Toro & Raza Vaca & $\mathrm{n}$ & $\begin{array}{c}\text { Natalidad } \\
\%\end{array}$ & $\begin{array}{c}\text { Mortalidad } \\
\%\end{array}$ & $\begin{array}{c}\text { Destete } \\
\%\end{array}$ \\
\hline SM & SM & 985 & 75.4 & 4.0 & 72.4 \\
SM & C & 321 & 78.3 & 2.5 & 76.3 \\
SM & F1 C $\times$ SM & 94 & 82.2 & 1.5 & 81.0 \\
C & SM & 213 & 69.1 & 2.0 & 67.7 \\
C & C & 433 & 79.2 & 8.5 & 72.5 \\
C & F1 SM $\times$ C & 192 & 81.6 & 1.5 & 80.4 \\
Ch/SG & F1 SM $\times$ C / C $\times$ SM & 105 & 59.0 & 5.0 & 56.0 \\
\hline
\end{tabular}

Adaptado de Martínez et al., 1996; Martínez y González, 2000 y Martínez y Flórez, 2012. 
Los valores medios de natalidad (74.9 \%) y destete $(72.3 \%)$, por vaca expuestas a toro, y el de mortalidad (3.6\%), por el número de terneros nacidos vivos, son indicadores superiores a los reportados en la región: natalidad $65 \%$, destete $58.5 \%$ y mortalidad $10 \%$ (FEDEGAN, 2006). Las tasas de natalidad (59.9 \%) y destete (56.0 \%) en el promedio de los grupos con toros Ch y SG fueron inferiores a todos los grupos y a los indicadores medios de la región. La razón para este pobre comportamiento, con las vacas más fértiles, las híbridas, son atribuibles a la escasa aclimatación de los toros foráneos, especialmente el $\mathrm{Ch}$, dado que el SG por su composición con Brahman evidenció un ligero mejor desempeño.

Las mayores tasas de natalidad y destete se presentaron en los grupos de vacas cruzadas, excepto en los lotes con razas introducidas (Ch y SG). La menor natalidad de las vacas SM, en el grupo de apareamiento con toro $\mathrm{C}$, obedeció, según Martínez (1999), a la "discriminación racial" de los toros C con vacas SM (69.1\%), que repercutió negativamente en el comportamiento reproductivo general de las vacas criollas SM. Esta manifestación discriminatoria del toro $\mathrm{C}$ fue observado con otras razas criollas como Romo y BON (Castro et al., 1971 y Martínez et al., 1993).

La mayor tasa de mortalidad de terneros (8.5 \%), se presentó en el grupo $\mathrm{C} \times \mathrm{C}$, sus causas no fueron suficientemente documentadas; sin embargo, no fue raro observar casos de "síndrome de ternero débil" (Martínez, 1999).

\section{Valores de heterosis individual de rasgos reproductivos}

Las hembras cruzadas $\mathrm{F} 1 \mathrm{SM} \times \mathrm{C}$ y $\mathrm{C} \times \mathrm{SM}$ obtuvieron su primer parto más temprano (1 342.2 d) que el promedio de las puras SM y C $\left(\begin{array}{lllll}1 & 320.3 & \text { d), }\end{array}\right.$ aventajándolas en 192.1 d (6.4 meses-m-), y en 41.5 d (1.4 m) en el IEP, con valores de heterosis individual (hi) de $-14.5 \%$ y $-8.3 \%$, en forma respectiva, corroboran los hallazgos obtenidos en investigaciones similares con Romo (Hernández, 1981) y BON (Martínez et al., 1993; Vaca, 2002; Martínez y Flórez, 2012).

\section{Valores de heterosis individual y materna de rasgos de crecimiento}

Los valores de heterosis individual de pesos al nacer, destete, 16 meses de edad y ganancias diarias predestete y postdestete se estimaron del apareamiento dialélico de toros y vacas de las razas $\mathrm{SM}, \mathrm{C}$ y la heterosis materna de los correspondientes apareamientos de toros Ch y SG con vacas puras SM y $\mathrm{C}$ y sus híbridas recíprocas $\mathrm{F} 1 \mathrm{SM} \times \mathrm{C}$ y $\mathrm{C} \times \mathrm{SM}$, en el $\mathrm{CI}$ La Libertad durante los años 1971 a 1986.

Cuadro 3. Valores de heterosis individual (hi) y materna (hm) de peso al nacer (PN), destete (PD, 8 meses), 16 meses de edad (P16m) y ganancias diarias (g/d) predestete (GPD) y postdestete (GPPD) de Sanmartinero (SM), Cebú (C) y cruces con Charolais (Ch) y Santa Gertrudis (SG). CI La Libertad. 1971-1986.

\begin{tabular}{|c|c|c|c|c|c|}
\hline $\begin{array}{l}\text { Estimación } \\
\text { Heterosis }\end{array}$ & $\begin{array}{l}\mathrm{PN}, \\
\mathrm{kg}\end{array}$ & $\begin{array}{l}\text { GND, } \\
\mathrm{g} / \mathrm{d}\end{array}$ & $\begin{array}{c}\mathrm{PD}, \\
\mathrm{kg}\end{array}$ & $\begin{array}{l}\text { GPD, } \\
\text { g/d }\end{array}$ & $\begin{array}{c}\mathrm{P} 16 \mathrm{~m}, \\
\mathrm{~kg}\end{array}$ \\
\hline$\overline{\text { Puras P (SM y C) }}$ & 25.6 & 553.0 & 158.6 & 196.5 & 210.0 \\
\hline $\mathrm{F} 1 \mathrm{~S} \mathrm{SM} \times \mathrm{C}$ y $\mathrm{C} \times \mathrm{SM}$ & 28.2 & 611.0 & 174.9 & 284.5 & 247.0 \\
\hline Unid. Het Prom F1s - Prom P & 2.6 & 58.0 & 16.4 & 88.0 & 37.2 \\
\hline$\%$ Het $(\mathrm{F} 1-\mathrm{P}) / \mathrm{P}^{*} 100$ & 10.2 & 10.5 & 10.3 & 44.8 & 17.7 \\
\hline F1s: SG y Ch con SM y C & 29.4 & 615.0 & 177.0 & 258.0 & 241.6 \\
\hline F2s: $1 / 2 \mathrm{SG}$ o $1 / 2 \mathrm{Ch}[1 / 2(\mathrm{SM} \times \mathrm{C})]$ & 30.1 & 663.0 & 189.2 & 210.0 & 242.8 \\
\hline Unid. Het. Prom F2s - Prom F1s & 0.7 & 48.0 & 12.1 & -48.0 & 1.2 \\
\hline Het $($ F2s - F1s)/F1s)*100 & 2.5 & 7.8 & 6.9 & -18.6 & 0.5 \\
\hline
\end{tabular}

Adaptado de Martínez, 1999; Vaca, 2002.

Los valores de hi (Cuadro 3) variaron desde 10.0 hasta $44.8 \%$ para PN y GPD, respectivamente, y los de $\mathrm{hm}$ desde -18.6 hasta $7.8 \%$ para GPD y GND, respectivamente. Los valores de hi de las características predestete son similares a los reportados en estudios con BON y Romo (Martínez et al., 1994, Hernández, 1981), pero los valores para las características posdestete son superiores a los reportados en los estudios antes citados.

\section{Valores genéticos}

En el Cuadro 4 se presentan las heredabilidades $\left(\mathrm{h}^{2}\right.$ directas y maternas de SM y Cebú, y heterosis (efectos no aditivos) del hato SM, C y sus cruces para pesos al nacimiento, destete y ganancias de peso posdestete (Elzo et al., 1999). 
Las $\mathrm{h}^{2}$ en las razas SM y Cebú para los tres caracteres de crecimiento ( $\mathrm{PN}, \mathrm{PD}$ y GP) tuvieron valores similares. Las h2 para PN directo y materno, y GP directo y materno, fueron medianas (0.26 a 0.30 ), mientras que las de PD directo y materno, fueron bajas (0.08 a 0.10). Los autores (Elzo et al., 1999) concluyeron que, bajo las condiciones ambientales (suelo, clima, manejo, alimentación) de La Libertad, se esperaría que la selección por PN y GP daría resultados más rápidos que para $\mathrm{PD}$.

Los valores de interactibilidades, efectos no aditivos (heterosis individual), tanto directas como maternas fueron equivalentes y de similares magnitudes a las estimadas en estudios previos en el CI La Libertad (Martínez, 1999; Martínez et al., 2009a.)

Cuadro 4. Estimaciones de heredabilidades $\left(\mathrm{h}^{2}\right)$ intrarraciales, e interactibilidades (heterosis, het) para peso al nacimiento, peso al destete y ganancia de peso postdestete. CI La Libertad 1966 - 1995.

\begin{tabular}{|c|c|c|c|}
\hline Parámetro & $\begin{array}{c}\mathrm{h}^{2} \\
\text { Intrarracial aditivo } \\
\mathrm{SM} \\
\end{array}$ & $\begin{array}{c}\text { Efecto genético } \\
\mathrm{h}^{2} \\
\text { Intrarracial aditivo } \\
\text { Cebú } \\
\end{array}$ & $\begin{array}{c}\text { heterosis } \\
\text { Interracial } \\
\text { No aditivo SM/Cebú }\end{array}$ \\
\hline PN-Directo* & 0.26 & 0.30 & 0.22 \\
\hline PD-Directo* & 0.10 & 0.08 & 0.08 \\
\hline GP-Directo* & 0.44 & 0.37 & 0.30 \\
\hline PN-Materno** & 0.29 & 0.26 & 0.25 \\
\hline PD-Materno** & 0.11 & 0.10 & 0.08 \\
\hline GP-Materno** & 0.46 & 0.38 & 0.35 \\
\hline
\end{tabular}

$\mathrm{SM}=$ Sanmartinero. ${ }^{*}$ h2: calculadas por efectos directos. ${ }^{* *} \mathrm{~h}^{2}$ : calculadas por efectos maternos.

\section{Predicciones genéticas multirraciales}

Elzo et al., (1999) analizaron las diferencias esperadas de progenie (DEPs) aditivas, no aditivas y totales (directas y maternas en todos los casos) para rasgos de crecimiento pre y posdestete. El grupo de toros SM tuvo menores promedios de DEPs directas para PN y PD que las de toros C; sin embargo, el promedio de DEPs directos para GP de los toros SM fue igual al de toros C. Los valores multirraciales aditivos de predicción maternos, por el contrario, se comportaron de manera opuesta. Los promedios de DEPs maternos de los toros SM fueron los más elevados para PN, PD, y GP, que los de toros C, lo que corrobora los resultados de otras investigaciones (Martínez, 1999). Estos valores de DEPs indican que, en promedio, 1) progenies de toros C usados entre 1971 y 1995 en La Libertad tuvieron mayor habilidad propia aditiva de crecimiento que progenies de los toros SM usados en ese mismo período, y 2) que las hijas de toros SM usados entre 1971 y 1995 tuvieron una mayor habilidad materna aditiva (ej., mayor producción de leche) que las hijas de toros $\mathrm{C}$ usados durante esos años.

\section{Producción de carne al destete}

Como corolario de lo dicho anteriormente, en el Cuadro 5 se presenta el cálculo de producción de carne al destete por vaca expuesta a toro en el hato, obtenido al multiplicar el porcentaje de destete por el peso a dicha edad. Este cálculo permite estimar conjuntamente características de crecimiento y reproducción. Se presenta solamente para el tipo de cruzamientos que podría hacerse a nivel comercial. La escasa población de SM debería confinarse, especialmente las hembras, en hatos puros, utilizándolas en apareamiento con toros puros y estos, para uso en programas de mejoramiento del hato puro y para hibridación con vacadas comerciales de otras razas, especialmente $\mathrm{C}$.

Cuadro 5. Producción de carne al destete por vaca expuesta (kg/vaca/año) en apareamientos comerciales entre Sanmartinero (SM), Cebú (C) y sus cruces.

\begin{tabular}{cccccc}
\hline Raza toro & Raza vaca & $\begin{array}{c}\text { Destete, } \\
\%\end{array}$ & $\begin{array}{c}\mathrm{PD}, \\
\mathrm{kg}\end{array}$ & $\begin{array}{c}\mathrm{kg} / \mathrm{vaca} / \text { año, } \\
\mathrm{kg}\end{array}$ & $\begin{array}{c}\text { Relación/ cebú } \\
\%\end{array}$ \\
\hline $\mathrm{C}$ & $\mathrm{C}$ & 72.5 & 155.8 & 112.9 & 100.0 \\
$\mathrm{SM}$ & $\mathrm{C}$ & 76.3 & 171.8 & 131.1 & 116.0 \\
$\mathrm{SM}$ & $\mathrm{C} \times \mathrm{SM}$ & 81.0 & 178.4 & 144.5 & 127.9 \\
$\mathrm{C}$ & $\mathrm{SM} \times \mathrm{C}$ & 80.4 & 188.8 & 151.8 & 134.4 \\
$\mathrm{Ch} / \mathrm{SG}$ & $\mathrm{SM} \times \mathrm{C}+\mathrm{C} \times \mathrm{SM}$ & 56.0 & 189.3 & 106.0 & 93.8 \\
\hline
\end{tabular}

Adaptado de Martínez, 1999. 
En el Cuadro 5 se aprecia que los grupos de dihíbridos producen significativamente más carne por vaca expuesta a toro en el hato que el grupo $\mathrm{C} \times \mathrm{C}$, debido no solo a los mayores índices de destete sino de mayor peso a dicha edad. Los valores porcentuales oscilaron entre 16 y $34 \%$, es decir entre 18.2 y $38.9 \mathrm{~kg}$ más por vaca expuesta, comparados con el grupo $\mathrm{C} \times \mathrm{C}$. Los mayores pesos al destete se obtuvieron en los trihíbridos con toro Ch y SG; sin embargo, el pobre comportamiento reproductivo de estos toros significó menor cantidad de carne por vaca expuesta (6.2\%) que el grupo de $\mathrm{C} \times \mathrm{C}$.

\section{Peso presacrificio y rendimiento en canal}

En estudios comparativos de acabado y rendimiento en canal, en dos localidades de la Orinoquia (piedemonte y altillanura), se encontró que animales en pastoreo con 36 meses de edad, el peso presacrificio, el de la canal fría y el rendimiento fueron ligeramente superiores en el C que en F1 SM×C: 473 vs. $469 \mathrm{~kg} ; 282$ vs. $267 \mathrm{~kg}$ y 59.6 vs. $56.9 \%$, respectivamente; sin embargo, los F1 presentaron canales más magras, con mayor cantidad de carne (65.5 vs. $62.0 \%$ ), menor cantidad de grasa de cobertura (12 vs. $16.5 \%$ ) y similar proporción de hueso (21 vs. 21 \%) (Gómez et al., 1984).

Así mismo, en una investigación posterior realizada en el Piedemonte del Meta sobre el efecto del grupo racial en el rendimiento y calidad de la carne (Martínez y Flórez, 2012; Flórez et al., 2014 ), se confirmó que el peso de la canal caliente y fría, y el rendimiento en canal fueron mayores en novillos Cebú comercial que en $\mathrm{SM} \times \mathrm{C}$, pero no se observaron diferencias en la edad y peso al sacrificio antes y después del ayuno, la merma por ayuno y la merma por enfriamiento de la canal.

El menor rendimiento en canal de los machos cruzados se debe en parte a que en los machos SM, el tren posterior tiene menor desarrollo (Martínez y González, 2000) frente a razas como el C, lo que puede afectar el peso y el rendimiento de la canal en los machos cruzados. De hecho, en trabajos de faenamiento realizados en ganado puro SM se observó en machos enteros de 43 meses de edad, un bajo peso al sacrificio y de la canal (425 y $219 \mathrm{~kg}$ ), con un rendimiento en canal fría de 51,6 \% (Flórez et al., 2014, Martínez y Flórez, 2012).

A pesar de que el rendimiento en canal es menor en el $\mathrm{SM}$ o los cruces de $\mathrm{SM} \times \mathrm{C}$, los diferentes estudios (Martínez y Flórez, 2012; Flórez et al., 2014) muestran que los machos cruzados presentaron canales más magras, con mayor cantidad de carne, menor cantidad de grasa de cobertura y similar proporción de hueso. Además, el total de carne aprovechable (TCA), que corresponde a la carne sin hueso ni grasa que se comercializa, es mayor en bovinos SM puros y cruces de $\mathrm{SM} \times \mathrm{C}$ en comparación con $\mathrm{C}$, debido a la mayor proporción de cortes y menor de grasa y hueso de estas canales. En resumen, las diferentes investigaciones revelan que los criollos SM y sus cruces con C, comparados con $\mathrm{C}$, tienen menor peso y rendimiento de la canal, pero al desposte por cada kilogramo de canal de bovinos SM y su cruce con C, se obtiene proporcionalmente más carne que en el $\mathrm{C}$.

\section{Calidad organoléptica de la carne}

La calidad organoléptica de la carne es un aspecto importante ya que impacta la aceptabilidad de la carne y la decisión de compra de los consumidores. La terneza y el sabor son los dos factores de calidad más significativos. Se han realizado una serie de investigaciones para evaluar estos atributos en ganado SM y sus cruces.

En general se encuentran algunas diferencias en la calidad instrumental de la carne entre bovinos SM, C y $\mathrm{SM} \times \mathrm{C}$. En una investigación realizada en el CI La Libertad, donde se compararon novillos cruzados de estos grupos raciales (Martínez y Flórez, 2012), se encontraron diferencias significativas que mostraron que los cortes de bovinos SM presentaron mayor humedad que los otros grupos raciales. Esto también se reflejó en los mayores porcentajes de agua libre y unida en el criollo con relación al C y los cruces. Los valores de terneza de cortes de lomo madurados por 14 días obtenidos en los criollos SM y cruzados permitieron clasificar la carne como tierna o medianamente tierna, la cual tiene un alto grado de aceptabilidad entre los consumidores. Además, no se observaron diferencias en el $\mathrm{pH}$ y las pérdidas por cocción entre grupos raciales.

Sin embargo, en estudios con cortes de carne madurados por 14 días del músculo Longissimus dorsi de bovinos SM, C y cruces con criollo SM, de concursos de ganado gordo, se encontró que la dureza de la carne fue mayor en el C (6.3 kgf), intermedia en $\mathrm{SM} \times \mathrm{C}(5.8$ kgf) y menor en SM (5.2 kgf), indicando que los cortes de carne de canales de bovinos SM y cruzados presentaron mejor terneza (un número menor equivale a una carne más blanda) que los cortes de carne de canales de novillos C (Flórez et al., 2015).

Al evaluar el color por métodos instrumentales, se encontró en una investigación realizada en el CI La 
Libertad (Flórez et al., 2015), que los cortes de carne del lomo de bovinos $\mathrm{C}$ fueron más luminosos, tuvieron mayor intensidad de color rojo y amarillo que los de $\mathrm{SM} \times \mathrm{C}$ y $\mathrm{SM}$, siendo estos últimos los cortes más oscuros, ya que provenían de canales de toros de 43 meses de edad.

\section{Composición nutricional de la carne}

Un estudio en el Piedemonte del Meta (Flórez et al., 2020) encontró que la carne del C tenía menor concentración de colesterol total frente a la de $\mathrm{SM} \times \mathrm{C}$, pero no se detectaron diferencias significativas en la materia seca, proteína cruda, extracto etéreo, cenizas y sustancias reactivas del ácido tiobarbitúrico (TBARS; estabilidad oxidativa) entre estos dos grupos raciales.

En cuanto a minerales, en ese mismo estudio, los cortes de $\mathrm{SM} \times \mathrm{C}$ tuvieron mayor concentración de potasio, fósforo, magnesio y zinc que los cortes de $\mathrm{C}$, pero tuvieron igual concentración de sodio, calcio y hierro. La menor concentración de minerales en los cortes de lomo del C con relación al $\mathrm{SM} \times \mathrm{C}$ pueden ser el resultado también de diferente concentración de la grasa intramuscular en entre los dos grupos raciales (Flórez et al., 2020).

En un trabajo realizado en el Centro de investigación La Libertad (Flórez, 2011), se encontró en promedio que los cortes de lomo de canales de novillos C presentaban mayor concentración del ácido palmítico y menor de esteárico que los cortes de novillos cruzados $\mathrm{SM} \times \mathrm{C}$. Con relación a la calidad sensorial estudios realizados por CORPOICA (Flórez et al., 2020) encontraron que los panelistas calificaron como más tiernos los cortes de SM y de menor intensidad de sabor que los de C.

\section{Producción de leche}

El estudio para determinar la producción de leche se llevó a cabo en el Centro Agropecuario Los Naranjos, municipo de Granada (Meta), ubicación representativa del BMHT, con suelos fértiles y alto grado de acidez. Se midió, entre 1981 y 1990, la producción de leche de $\mathrm{SM}$, mantenido en pastoreo rotacional (2.8 animales/ha) de Brachiaria humidícola (80 \%) y Brachiaria decumbens (20 \%) (González et al., 1995). Se utilizó monta directa en apareamiento continuo, con suplementación mineral de $8 \%$ de fósforo en forma permanente y a voluntad. El ordeño se realizó en forma manual, con algún consumo del ternero. La producción media de leche, en lactancias de 240 días, fue de $790 \mathrm{~kg}$.
Onofre et al., (2015) estimaron la producción y calidad de leche del SM, BON y HV en ordeño con ternero y encontaron que la producción media del SM fue $2.5 \mathrm{~L} / \mathrm{d}$, con valores máximos de 6.8 , valores inferiores a los de BON y HV; sin embargo, el mayor peso al destete correspondió a los teneros SM $(166 \mathrm{~kg})$. El porcentaje de grasa en la leche fue $3.6 \%$ inferior a las otras dos razas criollas, pero su proteina (13.7 \%) fue superior a la de HV (12.9 \%). En sólidos totales el SM (13.3 \%) superó al HV (12.9 \%) pero fue inferior al BON (13.7 \%). La cantidad de leche requerida para elaborar microquesos fue similar a la del $\mathrm{HV}$, se necesitaron $200 \mathrm{ml}$ de leche para obtener $41 \mathrm{~g}$ de queso.

\section{Pruebas de desempeño en pastoreo}

Las pruebas de desempeño animal se realizan como una estrategia para la mejora genética de la raza criolla $\mathrm{SM}$, producto de la cooperación técnico-científica entre AGROSAVIA y la Asociación de Criadores de Bovinos de Razas Criollas y Colombianas de los Llanos Orientales (ASOCRIOLLANOS).

Entre los años 2015 y 2018, se realizaron tres pruebas (I, II, III) de desempeño en pastoreo de toretes SM provenientes del Banco de Germoplasma y núcleo de mejoramiento de AGROSAVIA de los CI La Libertad y Carimagua, y de criadores de la raza, socios de ASOCRIOLLANOS (Flórez et al., 2016; Flórez et al., 2017; Rosero et al., 2020). Las pruebas se desarrollaron en el CI La Libertad en potreros de Brachiaria humidicola cv. dictyoneura con suplementación de sal mineralizada del $8 \%$ de fósforo. En estas tres pruebas, un total de 57 toretes provenientes de siete hatos del departamento del Meta se evaluaron y seleccionaron para las características de interés genético y económico. Los resultados más sobresalientes como ganancia diaria de peso, área del ojo del lomo, circunferencia escrotal y calificación visual o tipo se pueden ver en el Cuadro 6.

A partir de las estimaciones de los rasgos evaluados se desarrolló un índice de toro (IT), que incluyó la suma del ponderado del índice de gananacia media de peso (30 \%), el índice del área del ojo del lomo (30 \%), el índice de reproducción (30 \%) y el índice de tipo (10 $\%)$, para efectuar la clasificación de los mejores ejemplares, los cuales son utilizados para colecta y conservación (los dos mejores) de material seminal como una estrategia de mejora genética de los hatos a través de inseminación artificial, y para promover entre criadores de la raza y comerciales el 
mejoramiento genético de sus hatos. En enero de 2020 finalizó la cuarta prueba de desempeño en pastoreo y en septiembre de 2020 se dio inicio a la quinta prueba (datos no presentados).

Cuadro 6. Promedios de las principales variables medidas durante pruebas de desempeño en pastoreo de toretes Sanmartinero (SM). CI La Libertad. 2015 - 2018.

\begin{tabular}{ccccc}
\hline Prueba & $\begin{array}{c}\text { Ganancia media } \\
\text { diaria de peso } \\
(\mathrm{kg} / \text { animal/d) }\end{array}$ & $\begin{array}{c}\text { Área del ojo del } \\
\text { lomo promedio } \\
\left(\mathrm{cm}^{2}\right)\end{array}$ & $\begin{array}{c}\text { Circunferencia } \\
\text { escrotal promedio } \\
(\mathrm{cm})\end{array}$ & $\begin{array}{c}\text { Calificación visual } \\
\text { o tipo promedio } \\
(\text { puntos/100) }\end{array}$ \\
\hline I & 0.668 & 54.9 & 35.2 & 88.0 \\
II & 0.663 & 49.6 & 35.1 & 82.6 \\
III & 0.625 & 54.5 & 34.4 & 80.5 \\
\hline
\end{tabular}

\section{Investigación en fincas}

No existe mucha información consistente sobre investigación en fincas; sin embargo, en la Cuadro 7 se resumen algunos resultados sobre el uso de toros SM y C en fincas de la Altillanura y Piedemonte del Meta. Con el propósito de mostrar en finca las bondades de la hibridación entre el SM y el C se realizó, durante los años 1993 y 1994 en la Hacienda Santa Helena (Acacias, Meta), con condiciones ambientales similares a las del CI La Libertad, un plan de apareamiento de vacas $\mathrm{C}$, de alto mestizaje, con toros SM y C (Brahman). El hato estaba compuesto por 120 vacas de diferentes edades y condición fisiológica: secas, lactantes y novillas, y al iniciar el ensayo, el $50 \%$ de las hembras estaban vacías. El toro SM procedía de La Libertad y el C de la finca Santa Helena. La superioridad del toro SM fue manifiesta tanto en reproducción como en peso al destete, y ello significó $87.4 \mathrm{~kg}$ (79.0 \%) más de carne por vaca expuesta a toro.
Con el auspicio del Ministerio de Agricultura y Desarrollo Rural, Martínez y Chaves (2001) realizaron, entre 1998 y 2001, un experimento en cinco fincas del Piedemonte y Altillanura, y encontraron, en promedio, $11.1 \%$ de superioridad en las tasas de natalidad y destete de los grupos de apareamiento del toro criollo SM sobre los C (Brahman), corroborando los hallazgos de los centros experimentales. La proporción de vacas apareadas en cada caso fue superior en los lotes con toro criollo; el promedio de vacas por toro fue de 47, variando desde 35 hasta 100; mientras que, en el C, el promedio fue de 29, y osciló entre 15 y 35 vacas. En la Cuadro 7 se presentan los cálculos de la producción de carne al destete por grupo racial del toro y por vaca expuesta y, en todos los casos los gupos con toro SM hubo superioridad manifiesta en la producción por vaca expuesta.

Cuadro 7. Cálculo de la producción de carne al destete en apareamientos de hembras Cebú comercial con reproductores Brahman y Sanmartinero (SM) en fincas de la Altillanura y Piedemonte del Meta.

\begin{tabular}{cccccccc}
\hline GRUPO & $\begin{array}{c}\text { No. } \\
\text { Toros }\end{array}$ & $\begin{array}{c}\text { No. } \\
\text { Vacas }\end{array}$ & $\begin{array}{c}\text { Total } \\
\text { Terneros }\end{array}$ & $\begin{array}{c}\text { Destete } \\
\%\end{array}$ & $\begin{array}{c}\text { Peso } \\
\text { destete kg }\end{array}$ & $\begin{array}{c}\text { kg } \\
\text { terneros/vaca }\end{array}$ & Autores \\
\hline Brahman & 1 & 30 & 18 & 60.0 & 184.3 & 110.6 & Martínez y Jiménez, 1996 \\
SM & 1 & 30 & 28 & 93.3 & 221.2 & 198.0 & Martínez y Chaves, 2001 \\
Brahman & 9 & 332 & 216 & 65.0 & 159.1 & 103.4 & 125.6 \\
SM & 5 & 355 & 270 & 76.1 & 165.1 & 10 & \\
\hline
\end{tabular}

En el año 2005, la Corporación Colombiana de Investigación Agropecuaria, CORPOICA (Vásquez et al., 2015) inició, un programa de fomento, multiplicación y uso de las razas criollas en fincas de productores comerciales de diferentes regiones de Colombia. Mediante procedimientos especiales de selección de los ganaderos beneficiados del programa, se procedió a hacerles entrega a cada uno de ellos lotes de aproximadamente 20 a 25 hembras y dos toros criollos de las razas Romo, CCC, BON y SM. Uno de los toros se uso para el servicio de las hembras puras entregadas y el segundo para utilizar en apareamiento (cruzamiento) con las hembras cebuínas de propiedad de los beneficiarios.

Los animales entregados pertenecían a los bancos de germoplasma in situ de los distintos Centros de Investigación de la Corporación, de donde se seleccionaron un total de 1942 animales que fueron distribuidos en 131 núcleos para ser entregados a los productores, y a partir de estos se generó información para la evaluación de los parámetros productivos. 
Como resultado, al cabo de cinco años, se registró un total de 6264 animales es decir un incremento del 418 $\%$ en el tamaño total de la población objeto del Programa de Fomento. Con respecto al desempeño productivo, tomando en conjunto todas las razas criollas entregadas, los parámetros de crecimiento presentaron un comportamiento superior al valor promedio de la ganadería en Colombia, con un peso al destete (PD) de $148 \mathrm{~kg}$; una ganancia media diaria (GP) de $486 \mathrm{~g}$; lo que representa una edad al sacrificio (ES) de 30 a 36 meses; con un peso al sacrificio (PS) de $450 \mathrm{~kg}$; en cuanto al desempeño reproductivo, la edad al primer parto (EPP) fue de 40 meses con un intervalo entre partos (IEP) de 490 días, lo que representa una media de fertilidad de $70 \%$.

Los valores medios obtenidos en las fincas que recibieron ejemplares de la raza SM, fueron: EPP, 40 meses, IEP, 599 días y natalidad de $67.5 \%$. Para rasgos de crecimiento, PN, $27 \mathrm{~kg}, \mathrm{PD}$ (8 meses), $151 \mathrm{~kg}$ ganancia predestete, $416 \mathrm{~g} / \mathrm{d}$, y edad y peso sacrificio de 36 meses y $450 \mathrm{~kg}$ respectivamente. La mortalidad fue alta, $14 \%$. Los valores medios fueron inferiores a los reportados en el Centro de Investigación, pero superan ampliamente a la media de la ganadería colombiana (FEDEGAN, 2006), EPP, 6o meses, IEP, 695 días y natalidad de 55 \%. Para rasgos de crecimiento, PN, $30 \mathrm{~kg}$, PD (8 meses), $144 \mathrm{~kg}$ ganancia predestete, $400 \mathrm{~g} / \mathrm{d}$ y edad y peso sacrificio de 42 meses y $450 \mathrm{~kg}$ y mortalidad del $10 \%$.

Martínez et al., (2015) estudiaron, en la altillanura colombiana, finca Hato Chico (San Martín, Meta), el comportamiento reproductivo y crecimiento predestete de un hato de SM puro y de Cebú comercial (CC), este último en apareamiento con toros puros $\mathrm{C}$ (Brahman) y criollos (Romo, BON y SM). La EPP, 1021d y el IEP $524 \mathrm{~d}$ en el hato SM fueron menores en 57 y 13 días a los indicadores reproductivos de las hembras CC. Las hembras F1 SM presentaron valores ligeramente mayores para EPP (1081 d) e inferiores para IEP (501 d).

Peña et al. (2020) analizaron la información reproductiva de un hato de cría compuesto de vacas $\mathrm{C}$ comercial (CC) tipo Brahman (Br) apareadas en forma continua (absorción) con toros criollos SM. Los valores medios de EPP e IEP fueron de 3.8 años y 424.8 d. Los grupos de 50 y $63 \%$ de herencia SM fueron los que presentaron la menor EPP (3.4 y 2.7 años); así mismo, los menores IEP fueron los de los grupos 50 y o \% de herencia SM (413.5 y $422.1 \mathrm{~d}$ ). Los autores concluyeron que las hembras cruzadas con toros criollos de la raza SM son competitivas en reproducción y, en consecuencia, más sostenibles en sistemas de producción del trópico bajo húmedo colombiano.

\section{Caracterización genética molecular}

Las primeras aproximaciones moleculares que tuvieron como propósito medir distancias genéticas entre razas criollas, datan del año 1984 (Mejía et al., 1988); en dicho estudio se analizaron cinco proteínas séricas en cuatro razas criollas: BON, SM, Romo y CCC y se encontró que las razas BON, Romo y CCC eran las más cercanas entre sí, mientras que la SM conformaba un grupo más distante. Posteriormente, Moreno et al., (2001) utilizaron marcadores moleculares basados en ácidos nucleicos, específicamente polimorfismos de secuencias cortas repetidas en tándem (STRs) o más conocidos como microsatélites; analizando siete de estos marcadores para determinar la diversidad genética de todas las razas criollas colombianas, incluyendo al $\mathrm{C}$ como control externo; encontraron que en el lado que agrupa al SM era más cercano a las razas BON, Romo, CCC y HV, y más distante del Chino, CAS y C.

Trabajos recientes por De Leon et al., (2019) asociaron los genomas BON y SM con características de adaptación, calculadas por medio de coeficientes de adaptabilidad, tolerancia al calor, intervalo entre partos y edad al primer parto, usando 58868 y 57482 polimorfismos de nucleótido simple (SNPs) obtenidos de 1262 bovinos de raza BON y 742 de la raza SM, respectivamente. Estos autores encontraron 25 regiones en el BON y 11 en el SM asociadas a estas características de adaptación, así como varios genes presentes en dichas regiones, entre los cuales destacan a RPTOR, TM2D1, RAB21 y ACOT13, y relacionados con reproducción los genes SLC6A16, TMEM5OA, NLRP9, KHDRBS2.

Montoya et al., (2009) realizaron un estudio para determinar la asociación de los polimorfismos de tres marcadores moleculares del gen leptina, hormona asociada a diferentes características productivas y reproductivas de los animales de granja, con peso corporal, área de ojo de lomo (AOL), espesor de grasa dorsal (EGD), características medidas a partir de imágenes de ultrasonido. Estos autores encontraron que la mayor frecuencia alélica del alelo T (SNP), asociado con mayor marmorero, se presentó en la raza SM (o.66) y la menor en la Chino.

En diferentes estudios realizados por AGROSAVIA (información sin publicar) sobre genes de importancia 
económica, se han registrado frecuencias allicas altas para raza SM de genes asociados con fertilidad como Leptin AL457 y Leptin A59V con frecuencias de 0.85 y 0.97 respectivamente; en genes asociados con calidad, producción y otras características en leche se encontraron los siguientes valores: leptin A252T (1.00), leptin C963T (o.68), leptin T945M (o.57) y para genes asociados a calidad de carne como calpain 316 y wsucast, reportaron valores de 0.08 y 0.61 , respectivamente.
Onofre et al., (2015), determinaron producción y calidad de leche en SM, BON y HV, encontrando, en las tres razas, que las frecuencias de los alelos de Kappa Caseína A y Kappa Caseína B fueron para BON de 0.54 para alelo A y de 0.46 para el alelo B, mientras que en SM y HV el alelo A presentó mayor frecuencia que el B y dichas frecuencias en SM fueron: A $0.75 \mathrm{y}$ 0.25 para $\mathrm{B}$.

\section{Conclusiones y Recomendaciones}

La Orinoquia colombiana, conforme las descripciones de Holdrige y Hunter (1961), Santos (1989) y Huertas (1998) es una región caracterizada por condiciones climáticas adversas, suelos de escasa fertilidad y forrajes fibrosos, no apta para la explotación de razas europeas seleccionadas en ambientes y manejo mejorados, con costos elevados, principalmente de alimentación, los cuales no permiten un grado de rentabilidad aceptable para la ganadería tropical y muy especialmente para sistemas extensivos, con base en pastoreo y uso limitado de insumos externos. El ganado criollo SM por sus sobresalientes características adaptativas, reflejadas en adecuadas tasas de reproducción y sobrevivencia y, especialmente, por su gran habilidad combinatoria con el C, es una alternativa competitiva y sustentable para mejorar la producción, rentabilidad y calidad del producto final, principalmente carne, de los sistemas de cría y leche de la Orinoquia Colombiana.

Dado el escaso tamaño de la población y la poca aceptación de los ganaderos para utilizar las razas criollas en general y el SM en particular, el esfuerzo primario con el SM debería orientarse a su multiplicación, es decir, a utilizar en forma racional y sostenible las hembras en programas de apareamiento con toros de su misma raza y nunca en planes de cruzamientos, a menos que se trate de otras necesidades de investigación futuras; de la misma manera, y con el propósito de promover su multiplicación y desarrollo, se debe estimular el uso de toros SM en cruzamiento absorbente con vacadas comerciales tanto en sistemas de cría (carne) como en sistemas en doble propósito.

\section{Literatura Citada}

Abrew, V. H. A. 1999. El bovino de raza sanmartinera entre el desarraigo criollo y la voracidad comercial. VI. Simposio Internacional de Historia de los Llanos Colombo - Venezolanos. Villavicencio, Julio 20 de 1999.

Castro, A., L. H. Reyes y E. Velasco. 1971. Estudio sobre la discriminación racial de las razas Cebú y Romosinuano. Asoc. Lat. Prod. Anim. 6:178 (Memoria).

De León, C., Manrique, C., Martínez R., and Rocha, J. F. 2019. Genomic association study for adaptability traits in four Colombian cattle breeds. Genetics and Molecular Research 18(3): gmr18373 CFUNPECwww.funpecrp.com.br.

De Alba, M. J. 2009. El libro de los bovinos criollos de América. Montecillo, Texcoco, México, 443 págs.

Delgado J. V., Camacho, M. E., Benavente, M. F., Villalobos, A., Álvarez, L. A., Martínez, G., Yunda, H., Corredor, C. A., Toalombo, P., Cartuche, L., Zambrano, D., Vargas, J., Avilés, D., Aguirre, L., Llambí, S., Castro, G., Cruz, A., Carolino, N., Barba,
C. J., Navas, F. J. 2020. Estimación de censos raciales nacionales, resultados de la experiencia. CONBIAND-FAO. En: Anais do XX Simpósio Iberoamericano sobre Conservação e Uso de Recursos Zoogenéticos Locais. Pg 92.

Elzo, M., Martínez, G., González, F. y Huertas, H. 1999. Variabilidad y predicciones genéticas aditivas, noaditivas, y totales para características de carne en el rebaño multirracial sanmartinero-cebú de la libertad. Rev. CORPOICA, 3(2): 51-64. Bogotá D.C.

FAO. 2018. Sistema de Información sobre la Diversidad de los Animales Domésticos (DAD-IS) http://www.fao.org/dad-is/browse-by-country-andspecies/es/

FEDEGAN. 2006. PLAN ESTRATEGICO DE LA GANADERIA COLOMBIANA 2019. [ed.] José Félix Lafaurie Rivera. Primera Edición. Bogota D.C.: San Martin Obregón \& Cia, 2006. pág. 294. ISBN 978958-98018-1-9. https://www.fedegan.org.co/planestrategico-de-la-ganaderia-colombiana-2019 
Flórez, Díaz, H., Parra, J.L., Gómez, M., Rincón, G. 1998. Inmunidad pasiva de terneros criollo SM y su relación con el estado sanitario y el crecimiento bajo condiciones tropicales. Memorias del Cuarto Congreso Iberoamericano de Razas Nativas y Criollas. Tampico, Tamaulipas, México.

Flórez Díaz, H. 2011. Estrategias para mejorar la calidad de la carne bovina en Colombia. Memorias Primer congreso internacional de ciencia y tecnología de la carne. Bogotá 15-18 de marzo de 2011. 34pp.

Flórez Díaz, H.; Martínez Correal, G., Ballesteros Chavarro, H., León Llanos, L.M., Castañeda, S., Moreno Moreno, E., Arias Castellanos, L. E., Torres Cardona, J. C., Rodríguez Rojas, C. A., Peña Castellanos, F., Uribe Botero, A. 2014. Rendimiento en carne de bovinos criollos y europeos y sus cruces con Cebú en las condiciones de la Orinoquia colombiana. Revista AICA, 4:12-15. ISSN (versión impresa): 2253-7325; ISSN (versión web online): 2253-9727.

http://www.uco.es/conbiand/aica/templatemo_110 _lin_photo/articulos/2014/Trabajo041_AICA2014. pdf

Flórez Díaz, H., León Llanos, L. M., Ballesteros Chavarro, H., Castañeda, S., Moreno Moreno, E., Martínez Correal, G., Torres Cardona, J. C., Peña Castellanos, F. 2015. Calidad de la carne de bovinos criollos y europeos y sus cruces con Cebú en las condiciones de la Orinoquia colombiana. Revista AICA, 4:12-15. ISSN (versión impresa): 2253-7325; ISSN (versión web online): 2253-9727. https://aicarevista.jimdo.com/n $\% \mathrm{C}_{3}$ \%BAmeros/vol \%C3 \%BAmen-6-2015/

Flórez Díaz, H., Rincón A., Velásquez J. G., Onofre H. G., Peña M. A., Martínez G., Torres J.C., Hernández R. 2016. Primera prueba de desempeño en pastoreo de toretes criollo Sanmartinero. Resumen. Libro de Resúmenes. Simposio Iberoamericano sobre Conservación y Utilización de Recursos Zoogenéticos. Corrientes, Argentina. 9, 10 y 11 de noviembre $2016.2169 p$. https://conbiand2016argentina.files.wordpress.com /2016/12/memorias-del-xvii-simposio-conbiand.pdf

Flórez Díaz, H., Martínez G., Velásquez J. G., León L.M., Rincón A., Peña M. A., Onofre H. G., Rodríguez C. A., Hernández R. 2017. Segunda prueba de desempeño en pastoreo de toretes criollo Sanmartinero. Resúmenes XVIII Simposio Iberoamericano sobre conservación y utilización de recursos zoognéticos. 25 al 27 de octubre de 2017. Chiquimula Guatemala. Universidad de San Carlos de Guatemala, Centro Universitario de Oriente, Editorial Universitaria. 176p. http://www.uco.es/conbiand/pdf/acta_guatemala2 017.pdf

Flórez Díaz, H., León, L. M., Moreno, E., Peña, F., Martínez, G. 2020. Calidad sensorial y composicional del músculo Longissimus dorsi de bovinos criollos y cruces en Colombia. Documentos 163. Anais do XX Simpósio Iberoamericano sobre Conservação e Uso de Recursos Zoogenéticos Locais. Raquel Soares Juliano Ana Helena Bergamin Marozzi Fernandes Andrea Alves do Egito Editores Técnicos. Resumo. 11 a 14 de novembro Corumbá MS Brasil. P 34. ISSN 1981-7233 Março/2020 http://www.uco.es/conbiand/documentos/XXResu men.pdf

Gómez, C. M., Flórez Díaz, H., Parra, A. J., L.; Rincon, T. G. 2000. Viabilidad, inmunidad pasiva y morbimortalidad de terneros en explotaciones doble propósito y cría del Piedemonte llanero colombiano. Congreso Mundial de Buiatria. 9021-9033. Proceedings. Punta del este Uruguay. 4-8 diciembre 2000.

Gómez, J., Huertas, H., González, F. 1984. Estudio de peso y rendimiento en canal de la raza Sanmartinera, Cebú y sus cruces en los Llanos Orientales. Rev. ICA, 19: 253-265. http://hdl.handle.net/20.500.12324/23423

González, H. F., Ortiz, J. P., Martínez C. G., y Huertas, R. H. 1995. Producción de leche con SM. Rev. Achagua. 1(3): 40 - 47.

González, G., Velásquez, J. G., Flórez, D. H., Cardozo, J., Parra, J. L. 1996. Homeorresis ácido base durante el posparto en vacas SM bajo condiciones tropicales. Memorias del Tercer Congreso Iberoamericano de Razas Autóctonas y Criollas. Santafé de Bogotá, Colombia.

González, H. F. 1999. Caracterización fenotípica de la raza Sanmartinera. En: Memorias. Seminario Internacional Caracterización Genética y Potencial Productivo del Ganado SM. Villavicencio, 28 de mayo de 1999. P 1.

Hernández, B. G. 1981. Las razas criollas colombianas para la producción de carne. Recursos Genéticos animales en América Latina. Ganado Criollo y especies de altura. Roma, Italia, FAO 22:52.

Holdrige, L. R., Hunter, J. R. 1961. Clave de las Asociaciones Climáticas del mundo y guía para el uso de la tierra en los trópicos. Suplemento de la Revista Académica Colombiana de Ciencias. 11(43):14. 
Huertas, R. H. 1998. Prospectiva de ecodesarrollo ganadero para la Orinoquia: Una visión sistémica. Rev. Amevezllanos. 2(1): 38-45.

Huertas, R. H., Huertas, H. A. 2015. Historiografía de la ganadería en la Orinoquia. En: Actas Iberoamericanas de Ciencias Animales. AICA. Vol. 6. Págs. $300-307$.

Jiménez L. J., Bejarano M., y Martínez, C. G. 1996. Circunferencia escrotal y su relación con edad, peso y características seminales de bovinos criollos SMs. En: Memorias del III Congreso Iberoamericano de Razas Autóctonas y Criollas. Santafé de Bogotá. 25 a 29 de noviembre de 1996.

Kimura, M. and Crow, J. F. 1963. On the maximum avoidance of inbreeding. Genet. Res. Camb. Great Britain. 399-415

Laborde, D., Holmes, C. y Garcia, J. 1998. Eficiencia reproductiva de dos líneas de vacas HolsteinFriesian que difieren genéticamente por peso. Proc. NZ. Soc. Anim. Prod., 58:73.

Martínez C. G, Frahm, R. R., Buchanan, D. S. y Geisert, R. D. 1993. Caracterización de la raza criolla Blanco Orejinegro (BON). III. Heterosis del comportamiento reproductivo de hembras BON, Cebú y sus cruces recíprocos. Rev. ICA. 28(4): 377388.

Martínez C. G, Frahm, R. R., Buchanan, D. S. 1994. Caracterización de la raza criolla Blanco Orejinegro (BON). IV. Heterosis del crecimiento predestete de BON, Cebú y sus cruces con Charolais y Santa Gertrudis. Rev. ICA. 29(2):135-150.

Martínez C. G., González, H. F., Huertas, R. H. 1996. Productividad de ganado SM y sus cruces con Charoláis y Santa Gertrudis. I. Heterosis de características reproductivas. En: Memorias. Tercer Congreso Iberoamericano de razas Autóctonas y Criollas. Santafé de Bogotá, D.C. noviembre de 1996.

Martínez C. G. y Jiménez, L. J. 1996. Comportamiento productivo de toros criollos Sanmartinero en fincas del piedemonte del Meta. En: Memorias. Tercer congreso Iberoamericano de Razas autóctonas y criollas. Santafé de Bogotá, D.C. Noviembre de 1996.

Martínez, C. G., Arenas, E. y Rincón, G. 1998. Relación del Tamaño y la eficiencia reproductiva de vacas criollas Sanmartinero. Memorias. IV Congreso Iberoamericano de razas autóctonas y criollas. Tampico, Tamaulipas - México.

Martínez C. G. 1.999. Potencial genético del ganado SM en sistemas de carne y doble propósito. Memorias. Seminario Internacional Caracterización Genética y Potencial Productivo del Ganado SM. Villavicencio, 28 de mayo de 1999. P 31-42.
Martínez, C. G., González, H. F. 2000. El ganado criollo SM (SM) y su potencial productivo. AGRI. UNEPFAO (Roma, Italia) 28: 7-18.

Martínez, C. G. y Chaves, M, G. 2001. Ganado criollo Sanmartinero. Alternativa genética sustentable para la producción bovina en la Orinoquia. ICA PRONATTA - CORPOICA y UNILLANOS. Villavicencio. 20-04-2001. 47p.

Martínez, V. G., Martínez, C G., Manrique, C. 2009 a. Estimación de parámetros genéticos de características de crecimiento pre-destete del bovino criollo de raza SM (SM). Rev. Orinoquia. Universidad de los Llanos. 13(2): 101 - 112.

Martínez, V. G., Martínez, C G., Manrique, C. 2009 b. Estimación de parámetros genéticos de edad al primer parto e intervalo entre partos de vacas criollas Sanmartineras (SM). Rev. Orinoquia. Universidad de los Llanos. 13(2): 113 - 125 .

Martínez C. G., Flórez D. H. 2012. Razones bio económicas de ser de las razas bovinas criollas y colombianas. Octubre de 2012. Memorias. 4 seminario internacional, exhibicion y remate de razas bovinas criollas y colombianas. San Martín, Meta, octubre 6 y $7 \quad$ de 2012. http://www.ganadocriollocolombiano.com/memori as

Martínez, A. M., Gama, L T., Cañón, J., Ginja, C., Delgado J. V., et al. 2012. Genetic Footprints of Iberian Cattle in America 500 Years after the Arrival of Columbus. PLOS ONE 7(11): e49066. https://doi.org/10.1371/journal.pone.0049066

Martínez C. G. 2013. Mating systems to control inbreeding in Colombia. En: FAO. 2013. Latin America. In vivo conservation of animal genetic resources. FAO Animal Production and Health Guidelines. No. 14. Rome. Box 41 Pg. 151. http://www.fao.org/docrep/o18/i3327e/i3327e.pdf

Martínez C. G., Torres, C. J. C., Guio, P., Ballesteros, H. 2015. Utilización de toros criollos y su efecto en rasgos de reproducción y crecimiento, en un sistema de cría en la Orinoquia colombiana. Rev. AICA. 5: 44-50.

Mejía, J. A., Hernández, G. y Martínez C, G. 1988. Caracterización de vacas de cuatro razas criollas colombianas por cinco proteínas séricas sanguíneas. Rev. ICA 23(4): 320-326.

Montoya, A. A. E., Cerón-Muñoz, M. F., Trujillo, B. E., Ramirez, T. E. J., Angel, M. P. A. 2009. Frecuencia de los marcadores del gen leptina en razas bovinas Criollas y colombianas: I. Romosinuano, Chino Santandereano, Sanmartinero y Velásquez. Rev. Cient. Fac. Cien. Vet. Univ. Zulia, 19(1): 38-48. 
Moreno, F., Bedoya, G., Der., J., Carvajal, L., Bermúdez, N., Zuluaga, F., Ossa, J., Verdugo, J., Estrada, L., Barrera, J., Scoth, D., Tobon, C., Ruiz, L. 2001. Diversidad y relaciones filogenéticas del ganado criollo colombiano. Rev. Corpoica 3(2):1723.

Obando, C. H. 1999. Evaluación in vitro de la penetración espermática del semen SM y Cebú (Brahman). En: Memorias. Seminario Internacional Caracterización genética y potencial productivo del ganado SM. Villavicencio, 28 de mayo de 1999. P 3142.

Onofre G., Parra J., Martínez, R., Cassalett, E., Velásquez, H. 2015. Potencial productivo y calidad de la leche de razas criollas Blanco Orejinegro, Hartón del Valle y Sanmartinero en piedemonte colombiano. Actas Iberoamericanas de Conservación Animal. Rev. AICA 5:15-17

Peña C. F., Martínez, G., Manrique, C. 2020. Comportamiento reproductivo de hato cebú en cruzamiento absorbente con toros criollos SM en Orinoquia colombiana. Documentos 163. Anais do XX Simpósio Iberoamericano sobre Conservação e Uso de Recursos Zoogenéticos Locais. Raquel Soares Juliano Ana Helena Bergamin Marozzi Fernandes Andrea Alves do Egito Editores Técnicos. Resumo. 11 a 14 de novembro Corumbá - MS Brasil. P 66. ISSN 1981-7233 Março/2020 http://www.uco.es/conbiand/documentos/XXResu men.pdf

Pinzón, M. E. 1991. Historia de la ganadería bovina en Colombia. Supl. Ganadero, 8(1) Segunda edición aumentada y corregida. 4:1:208. Banco Ganadero, $218 \mathrm{p}$.

Rosero, J.A., Florez, H., Martínez, G., León L M., Onofre, H. G., Velásquez, J.G. 2020. Resultados III prueba de desempeño de toretes Sanmartinero en pastoreo en condiciones del Piedemonte LlaneroMeta-Colombia. Documentos 163. Anais do XX Simpósio Iberoamericano sobre Conservação e Uso de Recursos Zoogenéticos Locais. Raquel Soares Juliano Ana Helena Bergamin Marozzi Fernandes Andrea Alves do Egito Editores Técnicos. Resumo. 11 a 14 de novembro Corumbá - MS Brasil. P 155. ISSN 1981-7233 Março/2020 http://www.uco.es/conbiand/documentos/XXResu men.pdf

Rouse, J. E. 1977. The criollo: Spanish cattle in the Americas. Norman, USA. University of Oklahoma Press. 303 pp.

Santos, R. A. 1983. La Orinoquia colombiana. Artículo del Boletín de la Sociedad Geográfica de Colombia. Número 118, Volumen 36. https://www.sogeocol.edu.co/documentos/la_orino quia_col.pdf
Vaca M. E. 2002. Análisis retrospectivo del comportamiento reproductivo y crecimiento predestete de un hato mixto de ganado criollo SM y Cebú y sus cruces recíprocos. Tesis. Fundación Universitaria Agraria De Colombia "UNIAGRARIA" Facultad de Ciencias Agropecuarias Programa Zootecnia Bogotá, junio de 2002.

Vásquez, R., Martínez, R., Gallego, J., Abuabara, Y., Pérez, J., Onofre, H., Polanco N., Silva J. 2015. Contribución del plan de fomento de razas criollas al tamaño poblacional de razas para producción en Colombia. Rev. AICA 6: 411-418.

Velásquez, J. G., Flórez, D. H., Cardozo, J. 1996 a. Respuesta fisiológica al estrés por calor en vacas criollo SM. Memorias del tercer congreso iberoamericano de razas autóctonas y criollas. Santafé de Bogotá, Colombia.

Velásquez, J. G., Flórez, D. H., Cardozo, J., Castro, A., González, G., Manrique, C. 1996b. Hematología, metabolitos y gases sanguíneos de terneros neonatos SM en el trópico bajo. Memorias del Tercer Congreso Iberoamericano de Razas Autóctonas y Criollas. Santafé de Bogotá, Colombia.

Velásquez, J. G., Flórez, D. H., Cardozo, J., González, G., Manrique, C. 1996c. Hematología, metabolitos y gases sanguíneos en el predestete de terneros criollo SM en el trópico bajo. Memorias del tercer congreso iberoamericano de razas autóctonas y criollas. Santafé de Bogotá, Colombia.

Velásquez, J. G., Flórez, D. H., Cardozo, J., González, G. 1998a. Termoregulación de terneros criollo SM bajo condiciones tropicales en Colombia. Memorias del Cuarto congreso iberoamericano de razas nativas y criollas. Tampico, Tamaulipas, México.

Velásquez, J. G., Flórez, D. H., Cardozo, J., Castro, A., Parra, J. L., Velásquez, H., Onofre, G., Jiménez, H. R., Villar, C., Góngora, A. 1998b. Tolerancia al estrés por calor en ganado criollo SM, Cebú, Holstein y $\mathrm{SM} \times \mathrm{C}$ en Colombia. Memorias del Cuarto congreso iberoamericano de razas nativas y criollas. Tampico, Tamaulipas, México.

Velásquez, P. G. 1999. Características fisiológicas de la raza SM. En: Memorias. Seminario Internacional Caracterización genética y potencial productivo del ganado SM. Villavicencio, 28 de mayo de 1999. P 819

Velásquez; J. G. Góngora, A., Vanegas, O., Parra, J. L., Flórez, H., Cardozo, J. 200o. Perfiles endocrinos, hemoglobina, y hematocrito durante el postparto de vacas SM. Rev. Orinoquia - Unillanos. 4(4): 109 123. ISBN - 0123 - 0212. 
Villalobos-Cortés, A. I. A, Martínez A. M., Delgado, B. J. V. 2009. Historia de los bovinos en Panamá y su relación con las poblaciones bovinas de Iberoamérica. Arch. Zootec. 58 (R): 121-129.
Villar, C. E., Martínez, C. G. 1996. Niveles de infestación por la garrapata Boophilus microplus en la progenie de dos toros SM suplementados con flor de azufre. En: Memorias. Tercer congreso Iberoamericano de Razas autóctonas y criollas. Santafé de Bogotá, D.C. noviembre de 1996. 